\title{
DÜBLIN
}

Technological University Dublin

ARROW@TU Dublin

\section{Sustainability of Grid-tie Micro-generation System}

\author{
Lubna Mariam \\ Technological University Dublin \\ Malabika Basu \\ Technological University Dublin, mbasu@tudublin.ie \\ Michael Conlon \\ Technological University Dublin, michael.conlon@tudublin.ie
}

Follow this and additional works at: https://arrow.tudublin.ie/engscheleart

Part of the Electrical and Computer Engineering Commons

\section{Recommended Citation}

Mariam, L.; Basu, M.; Conlon, M.F., "Sustainability of grid-tie micro-generation system," Power Engineering Conference (UPEC), 2013 48th International Universities' , vol., no., pp.1,6, 2-5 Sept. 2013 doi: 10.1109/ UPEC.2013.6715014

This Conference Paper is brought to you for free and open access by the School of Electrical and Electronic Engineering at ARROW@TU Dublin. It has been accepted for inclusion in Conference papers by an authorized administrator of ARROW@TU Dublin. For more information, please contact arrow.admin@tudublin.ie, aisling.coyne@tudublin.ie,gerard.connolly@tudublin.ie.

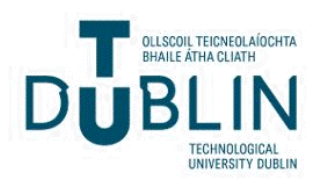




\section{Sustainability of Grid-tie Micro-generation System}

\author{
Lubna Mariam \\ School of Electrical and Electronic \\ Engineering, Dublin Institute of \\ Technology, Ireland \\ E-mail: lubna.mariam@gmail.com
}

\author{
Malabika Basu \\ School of Electrical and Electronic \\ Engineering, Dublin Institute of \\ Technology, Ireland \\ E-mail: mbasu@ieee.org
}

\author{
Michael F Conlon \\ School of Electrical and Electronic \\ Engineering, Dublin Institute of \\ Technology, Ireland \\ E-mail: Michael.conlon@dit.ie
}

\begin{abstract}
Both the outcomes of technical and economical feasibility analysis of a renewable based power system should be positive to achieve sustainability. Energy production or Renewable Energy Feed-in-Tariff (REFIT) cost should be lower or higher respectively than the existing grid electricity cost. As the renewable energy sources are variable and where REFIT is also applicable for the system connected to the grid, the detailed hourly time series analysis is very important. Based on this issue, in this paper, a techno-economic feasibility analysis has been performed for a PV based micro-generation system to find out the possible ways to make the micro-generation ( $\mu$ Gen) system sustainable in low irradiation region. As a case study, the city of Dublin, Ireland has been chosen for the detailed analysis. Analysis shows how the technological improvement can help to popularize the $\mu$ Gen system in Ireland. The procedure can be followed by other countries as well.
\end{abstract}

Index Terms-Renewable energy, PV system, microgeneration, techno-economic analysis, REFIT,

\section{INTRODUCTION}

Developing renewable energy sector is an important part of Ireland's energy sustainability and climate change strategy. Three energy policy goals are met with RE sources such as; energy security, cost competitiveness and protection of the environment through the reduction of greenhouse gas emission. Under EU Renewable Energy Directive $2009 / 28 /$ EC, Ireland's target is, at least $16 \%$ of all energy in the state will be consumed from renewable energy with a subtarget of $10 \%$ in the transport by 2020 [1]. Ireland also wants to achieve the target of $20 \%$ reduction of Green House Gas (GHG) emission by 2020 [2]. To achieve these targets between the timeline, first step should be maximizing penetration of Renewable/Green Energy (RE) in the energy sector. Photovoltaic (PV) system is a technology to produce electricity from solar energy which is becoming popular in many countries with high solar irradiation. Though Ireland is comparatively a low GHI (global horizontal irradiation) region, future of $\mathrm{PV}$ based micro-generation system can become a promising option in energy sector with some technological and economical improvement in the system.

Aim of the present work is to figure out few possible ways to reduce the energy production cost to make the PV system as a sustainable or viable micro-generation solution for Ireland. Therefore, some technical analysis has been done here a) to increase the energy production and b) to reduce the produced cost of energy. Increase of energy production is related to the implemented technology and optimum placement of the system based on geographical and environmental condition. Ireland is one of the countries in low irradiation region. Till now, very few researches/efforts have been made to popularize the PV based $\mu$ Gen system [3, 4]. Findings of these research work show that till now analysis has been done for 53 degree tilt fixed axis PV system and based on the current market price and REFIT policy, this system is not viable.

Therefore the following technical issues have been considered in this paper and analysed in details to improve the technical performance as well as increase the energy production of the system. This will help to reduce the cost of produced energy (COE) below the purchased grid electricity cost or the REFIT cost to make it sustainable. The considered issues are;

1. Optimum placement (tilted angle) of PV panel for a fixed axis system

2. Auto tracking system - (a) One axis (b) Two axis

\section{METHODOLOGY}

A simple PV based $\mu$ Gen system is presented in Fig 1. A methodology has also been prepared, as shown in Fig 2, to normalize the procedure for techno-economical analysis of a system (i) to improve the technical performance and (ii) to make it economically sustainable. Technical information of the system, economical information of the components and system installation, load demand of the end user and the georesource information of the location are used as the input to calculate the cost of energy (COE) of the proposed system. It is then compared with the present or existing base system (in this case - grid electricity cost). Technological improvements are then applied to achieve the sustainability. HOMER, powerful software for techno-economical analysis of renewable based power generation system $[5,6]$, has been used in the paper for partial analysis of the system. One of the main advantages of the software is that it deals with the hourly time series data and performs the analysis hourly. Therefore, hour-by-hour technical performance of the system can be observed. 

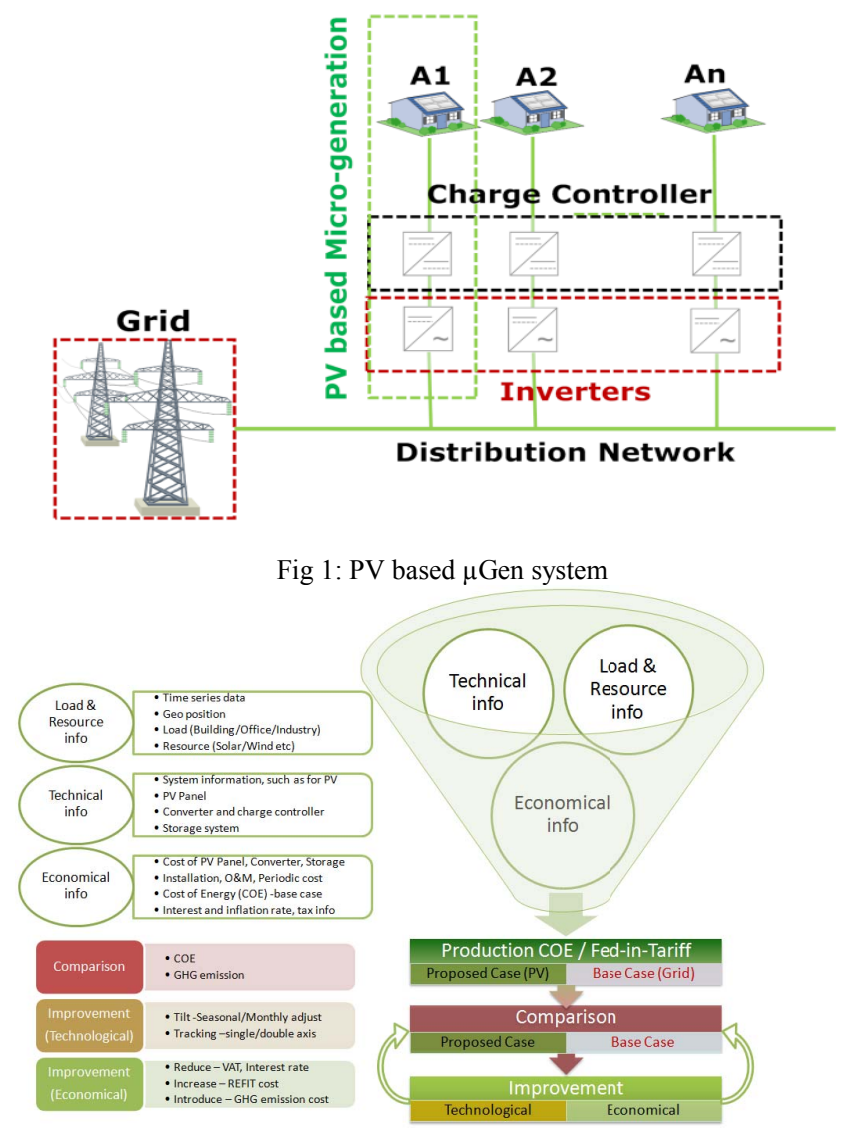

Fig 2: Methodology for techno-economic analysis

\section{III. $\mu$ GEN SCENARIO IN IRELAND}

According to Irish electricity board ESB Network Microgenerators are defined as grid connected generation up to maximum rating of $11 \mathrm{~kW}$ when connected to the 3 phase distribution grid $(400 \mathrm{~V})$ and $6 \mathrm{~kW}$ when connected to the single phase distribution grid (230V) [7]. Following this definition In Ireland, at the end of 2010 nearly 2 MW microgeneration system are grid connected among which solar PV installed capacity is $120.78 \mathrm{~kW}$ [7]. And the share of the $\mu \mathrm{Gen}$ system in the total energy production is less than $1 \%$ [8]. Irish Government has introduced incentives for $\mu$ Generators from early 2009 and these are free export/import meter, $9 \mathrm{c} / \mathrm{kWh}$ for all exported electricity, $10 \mathrm{c} / \mathrm{kWh}$ for the first $3000 \mathrm{kWh}$ exported [8]. But still PV micro-generator is not yet economically feasible in Ireland [3] and based on the market condition in 2011 and the prediction of PV systems price reduction, grid electricity cost escalation, PV based $\mu$ Gen can become feasible after 2016 [4]. Fig 3 shows the percentage of prominent renewable energy (RE) systems in total Irish electricity production [2]. Fig 4 shows gridconnected micro solar PV systems installed from January to October 2010, where it is observed that $80 \%$ of the systems have capacity upto $3 \mathrm{~kW}$ peak, may be result of restricted roof size, larger capital cost and long payback period of the system [3].

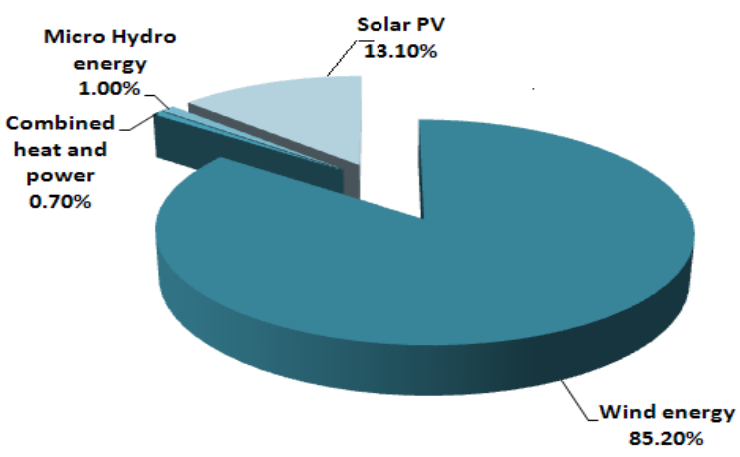

Fig 3: Share of RE system in total Irish electricity production

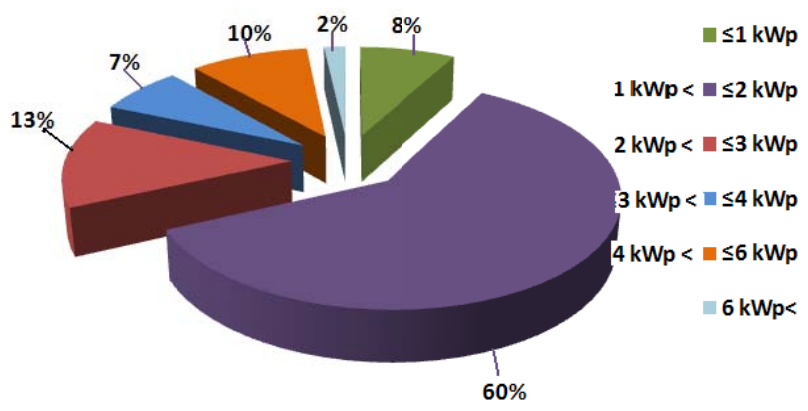

Fig 4: Grid connected micro-PV systems in Ireland

\section{SUN-TRACKING SYSTEMS}

In conventional fixed PV systems, the modules are oriented in such a position (tilt and azimuth) that ensures the highest solar irradiation. Position of the sun changes continuously over the time, therefore fixed angle tilted PV systems cannot get optimum solar radiation. This is one of the reasons for introducing tracking technology in the system. The racks that allow the collectors to track along the movement of the sun are quite costly. If the obtained solar radiation by the tracking system is not significant enough, the COE can increase. Suntracking systems can be classified into two categories.

\section{A. One axis tracking system:}

The system tracks the sun either in azimuth or in altitude angle. Single or one axis tracking is almost always done with a mount having manually adjustable tilt angle along northsouth axis and a tracking system that rotates the collector array from east to west. The equation of one axis tracking system is as follows [9],

$$
\begin{aligned}
& I_{B C}=I_{B} \cos \delta \\
& I_{D C}=C I_{B}\left[\frac{1+\cos \left(90^{\circ}-\beta+\delta\right)}{2}\right] \\
& I_{R C}=\rho\left(I_{B H}+I_{D H}\right)\left[\frac{1+\cos \left(90^{\circ}-\beta+\delta\right)}{2}\right] \\
& I_{B C}=B \text { eam radiation } \\
& I_{D C}=D \text { iffuse radiation } \\
& I_{R C}=\text { Reflected radiation } \\
& I_{D H}=\text { Horizontal diffuse radiation } \\
& I_{B H}=\text { Horizontal beam radiation } \\
& C=S \text { ky diffuse factor }
\end{aligned}
$$


$I_{B}=$ Direct beam radiation

$\beta=$ Tilt angle

$\delta=$ Declination

\section{B. Two axis tracking system}

The system tracks the sun in both azimuth and altitude angles so that the collectors are always pointing directly to the sun. The equation of two axis tracking system is as follows [9],

$I_{B C}=I_{B}$

$I_{D C}=C I_{B}\left[\frac{1+\cos \left(90^{\circ}-\beta\right)}{2}\right]$

$I_{R C}=\rho\left(I_{B H}+I_{D H}\right)\left[\frac{1+\cos \left(90^{\circ}-\beta\right)}{2}\right]$

C. Energy gain in sun-tracking system:

Existing studies show that introducing tracking systems in solar PV modules can achieve $30-40 \%$ gain in the annual radiation comparing to the same installation of fixed modules $[10,11]$. The city of Dublin in Ireland is located at 53 degree angle latitude, so the fixed solar panel systems are normally installed at that angle for better performance. Monthly averaged global horizontal irradiation (GHI) has been collected from [12]. Monthly averaged available radiation on a fixed tilt and tracking surface has been calculated. Fig 5 shows the ratio of solar radiation on tilted and horizontal $\left(G_{\beta} / G_{H}\right)$ along with the tracking surface. It indicates how much solar radiation can improve from fixed axis to one or two axis tracking system for Dublin location. It is observed from Fig 5 that, maximum $G_{\beta} / G_{H}$ is found to be $17 \%$ more than with a tilt angle of $38^{\circ}$ compared to no tilt. At $53^{\circ}$ tilt, this ratio is $15 \%$ which is commonly practiced in Dublin. Further improvement can be possible by introducing tracking system. With 1 -axis tracking at $38^{\circ}$ tilt it can improve maximum $45 \%$ whereas with 2 -axis tracking it increases to $49 \%$.

Table I shows the monthly average solar radiation values for these selected position and tracking systems, as shown in Fig 5. As a part of manual tracking system, monthly optimum (maximum radiation obtained at each month at a specific tilt angle) values can also be calculated, but this topic is beyond the area of this paper. It is observed that in case of fixed system, tilt at 53 degree can give better performance in winter months whereas 38 degree could be suitable for summer months (shown by the green colour). Annual average value for 38 and 53 degree angle is 3.06 and $3.00 \mathrm{kWh} / \mathrm{m}^{2}$, therefore it can be stated that PV panel at 38 degree angle can produce more electricity.

On the other hand solar radiation improves significantly for 1 -axis and 2-axis tracking system. In case of 1-axis system, both tilt at 38 and 53 degree show comparatively healthier improvement in the obtained radiation. Therefore, it can summarize that in case of Dublin, sun tracking PV system can achieve $40 \%-50 \%$ more solar energy annually compared to fixed axis system.

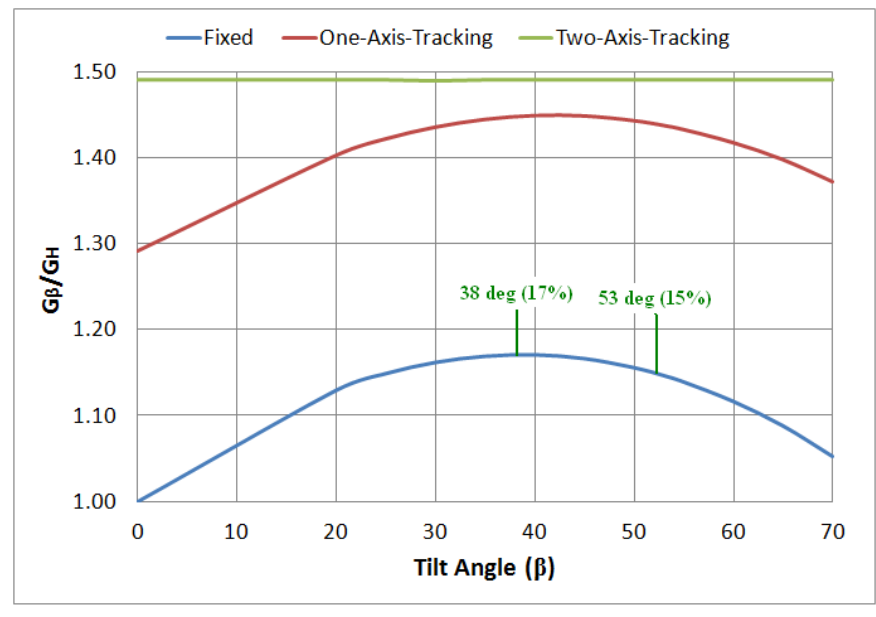

Fig 5: Ratio of solar radiation on Tilted $\left(G_{\beta}\right)$ and Horizontal $\left(G_{H}\right)$ surface in Dublin, Ireland

TABLE I

GLOBAL RADIATION (G), IN kWh/m²/day, ON HORIZONTAL (H) AND

\begin{tabular}{|l|c|c|c|c|c|c|}
\multicolumn{5}{c}{ TILTED ( $\beta$ SURFACE IN DUBLIN, IRELAND } \\
\cline { 2 - 7 } & \multicolumn{3}{|c|}{ Fixed } & \multicolumn{3}{c|}{ Tracking } \\
\cline { 2 - 7 } & 0 & 38 & 53 & 38 & 53 & $\begin{array}{c}\text { Two } \\
\text { Axis }\end{array}$ \\
\hline Janth & 0.71 & 1.49 & 1.67 & 1.71 & 1.87 & 1.94 \\
\hline Feb & 1.31 & 2.14 & 2.28 & 2.54 & 2.66 & 2.67 \\
\hline Mar & 2.86 & 3.98 & 4.07 & 5.10 & 5.17 & 5.16 \\
\hline Apr & 3.31 & 3.65 & 3.50 & 4.47 & 4.37 & 4.47 \\
\hline May & 4.75 & 4.77 & 4.43 & 6.28 & 6.06 & 6.42 \\
\hline Jun & 4.92 & 4.71 & 4.30 & 6.04 & 5.78 & 6.27 \\
\hline Jul & 4.70 & 4.59 & 4.22 & 5.90 & 5.66 & 6.07 \\
\hline Aug & 3.61 & 3.80 & 3.59 & 4.62 & 4.48 & 4.65 \\
\hline Sep & 2.40 & 2.84 & 2.79 & 3.30 & 3.27 & 3.28 \\
\hline Oct & 1.39 & 1.98 & 2.05 & 2.27 & 2.33 & 2.32 \\
\hline Nov & 0.81 & 1.61 & 1.67 & 1.84 & 1.86 & 1.90 \\
\hline Dec & 0.54 & 1.10 & 1.38 & 1.26 & 1.55 & 1.62 \\
\hline Ave & $\mathbf{2 . 6 2}$ & $\mathbf{3 . 0 6}$ & $\mathbf{3 . 0 0}$ & $\mathbf{3 . 7 9}$ & $\mathbf{3 . 7 6}$ & $\mathbf{3 . 9 0}$ \\
\hline $\begin{array}{l}\text { Annual } \\
\text { kWh/m }\end{array}$ & 955 & 1118 & 1095 & 1382 & 1373 & 1423 \\
\hline G $/$ /GH & $\mathbf{1 . 0}$ & $\mathbf{1 . 1 7}$ & $\mathbf{1 . 1 5}$ & $\mathbf{1 . 4 5}$ & $\mathbf{1 . 4 4}$ & $\mathbf{1 . 4 9}$ \\
\hline
\end{tabular}

\section{ANALYSIS}

For the overall analysis, technical and economical information of the system have been given in Table II and III respectively. Load information (load profile and per capita energy consumption) has been collected from the local authority [13]. PV Panel, tracking system and inverter cost information have been collected from different sources [14, $15,16]$.

Fig 6 shows the load profile $(\mathrm{kW} / \mathrm{h})$ of a single home user for four months (January, April, July, October) in Dublin, Ireland with solar radiation availability on those consecutive months. It is found that load consumption is relatively high $(>1.2 \mathrm{~kW} / \mathrm{h})$ in winter months at time $(17: 00 \mathrm{pm}-22: 00 \mathrm{pm})$. 
In those months the available solar radiation $\left(<0.2 \mathrm{kWh} / \mathrm{m}^{2}\right)$ during the time $(8: 00 \mathrm{am}-17: 00 \mathrm{pm})$ is not sufficient enough to produce electricity. In summer months, peak load demand is $(<1.0 \mathrm{~kW} / \mathrm{h})$ at the time $(17: 00 \mathrm{pm}-22: 00 \mathrm{pm})$. Solar radiation in those months is relatively high and suitable for electricity production. In both cases, the solar radiation and load demand pattern does not match at peak load hours.

TABLE II

TECHNOLOGICAL INFORMATION

\begin{tabular}{|l|l|}
\hline Peak Load & $1.7 \mathrm{kWp} /$ day per house (single user) \\
\hline Annual consumption & $5000 \mathrm{kWh} /$ year \\
\hline PV panel capacity & 1 to $6 \mathrm{~kW} /$ house \\
\hline Inverter capacity & 1 to $6 \mathrm{~kW} /$ house \\
\hline Fixed axis system & a) 53 degree tilt \\
& b) 38 degree tilt \\
\hline Tracking system & a) 1 -axis tracking \\
& b) 2 axis tracking \\
\hline
\end{tabular}

TABLE III

ECONOMICAL INFORMATION

\begin{tabular}{|l|c|}
\hline System & Cost \\
\hline PV panel & 1 to $4 € / \mathrm{Wp}$ \\
\hline 1-axis tracking system & $1 € / \mathrm{Wp}$ \\
\hline 2 axis tracking system & $1.2 € / \mathrm{Wp}$ \\
\hline Others (component + installation) & $0.5 € / \mathrm{Wp}$ \\
\hline Inverter cost & Calculated from cost curve \\
\hline
\end{tabular}

Based on the quality and materials, PV panel cost varies. In recent years, PV panel cost is also decreasing dramatically. Therefore, considering the decreasing trend and the possible cost in near future, PV panel cost has been varied from $€ 4.00$ to $€ 1.00$.

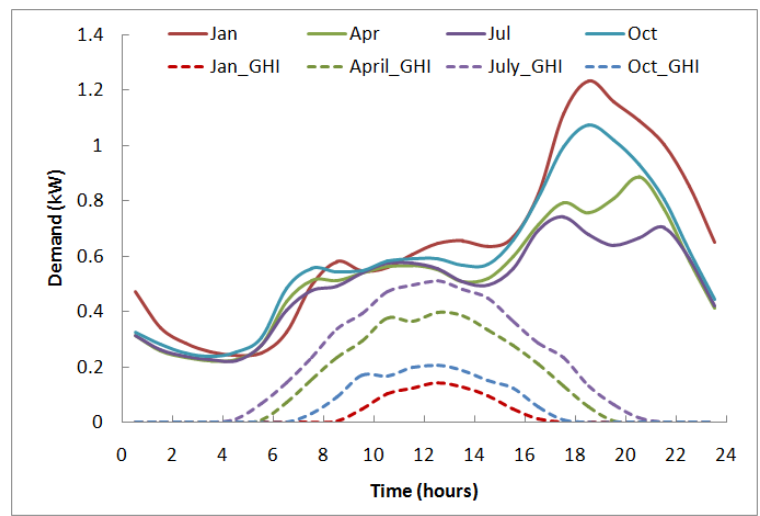

Fig 6: Load profile (-) and solar radiation pattern (--) for 4 months

The cost of converter $(€ / \mathrm{kW})$ also varies with the size/capacity. Based on the collected cost information of converter for different size/capacity from different manufacturer, a cost curve has been created, as shown in Fig 7.

Based on this techno-economical information, a gridconnected PV based $\mu \mathrm{Gen}$ system has been simulated in HOMER and the hourly performance is analyzed.

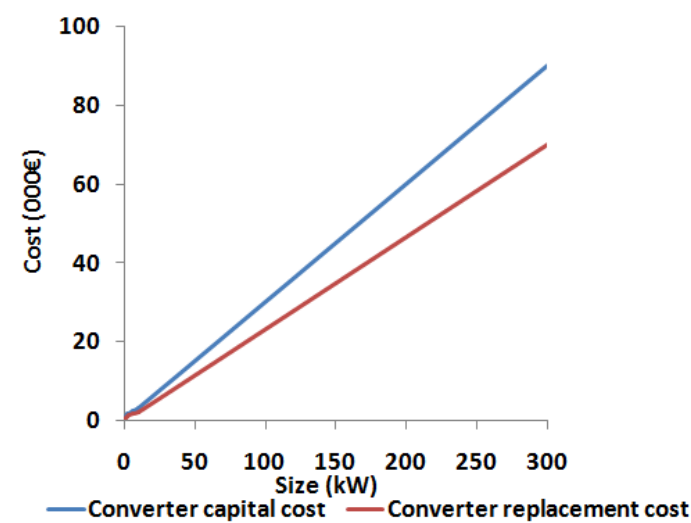

Fig. 7. Converter cost curve

\section{RESULT \& DISCUSSION}

Result has been discussed here for the installation of maximum capacity ( $6 \mathrm{~kW} \mu \mathrm{Gen}$ system). Table IV shows the advantages of $\mu$ Gen system. After installation, the household user can sell the additional energy produced by the system and thus can reduce purchasing energy from the grid. Analysis shows that for the fixed tilt at 53 degree, the system can sell more energy to the grid during the winter months. Whereas, tilt 38 degree shows better result for the summer months. Annual sell to the grid also high if the system is placed at 38 degree tilt angle.

Similar result is obtained for the auto tracking systems, as shown in Table V. Here it shows that two axis tracking gives the best output round the year and can sell energy more than that of one axis tracking system.

TABLE IV

ENERGY PURCHASED AND SOLD FOR $6 \mathrm{KW}$ PV BASED $\mu$ GEN SYSTEM (AT FIXED 53 AND 38 DEGREE ANGLE)

\begin{tabular}{|l|l|l|l|l|l|l|}
\hline \multirow{2}{*}{ Month } & \multicolumn{3}{|l|}{$\begin{array}{l}\text { Energy Purchased } \\
\mathrm{kWh})\end{array}$} & \multicolumn{2}{|l}{$\begin{array}{l}\text { Energy Sold } \\
(\mathrm{kWh})\end{array}$} & \multicolumn{2}{l|}{$\begin{array}{l}\text { Net Purchases } \\
(\mathrm{kWh})\end{array}$} \\
\hline & $\begin{array}{l}53 \\
\text { Deg }\end{array}$ & $\begin{array}{l}38 \\
\text { Deg }\end{array}$ & $\begin{array}{l}53 \\
\text { Deg }\end{array}$ & $\begin{array}{l}38 \\
\text { Deg }\end{array}$ & $\begin{array}{l}53 \\
\text { Deg }\end{array}$ & $\begin{array}{l}38 \\
\text { Deg }\end{array}$ \\
\hline Jan & 399 & 398 & 180 & 153 & 219 & 245 \\
\hline Feb & 295 & 294 & 219 & 194 & 76 & 100 \\
\hline Mar & 268 & 267 & 460 & 434 & -191 & -167 \\
\hline Apr & 239 & 235 & 311 & 325 & -72 & -90 \\
\hline May & 212 & 208 & 432 & 473 & -221 & -266 \\
\hline Jun & 184 & 179 & 385 & 432 & -201 & -253 \\
\hline Jul & 191 & 185 & 386 & 430 & -195 & -245 \\
\hline Aug & 221 & 214 & 322 & 343 & -102 & -130 \\
\hline Sep & 244 & 241 & 254 & 252 & -10 & -11 \\
\hline Oct & 270 & 267 & 164 & 152 & 105 & 115 \\
\hline Nov & 307 & 306 & 170 & 146 & 137 & 160 \\
\hline Dec & 364 & 363 & 119 & 100 & 245 & 163 \\
\hline Annual & 3,194 & 3,157 & 3,404 & 3,435 & -210 & -277 \\
\hline & & & & & & \\
\hline
\end{tabular}



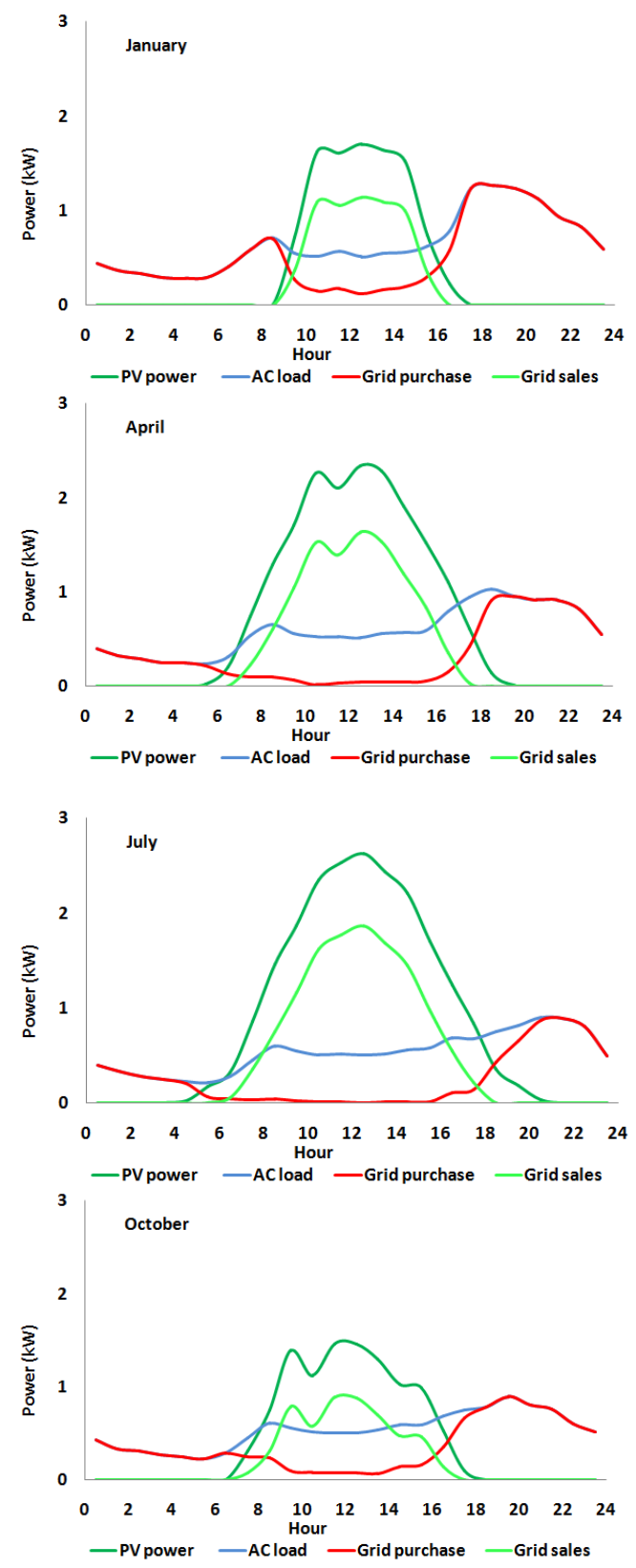

Fig 8: Hourly averaged load profile (AC load), energy production (PV power), sell to (Grid sales) and purchase from grid (Grid purchase) - Fixed axis tilt at 53 degree.
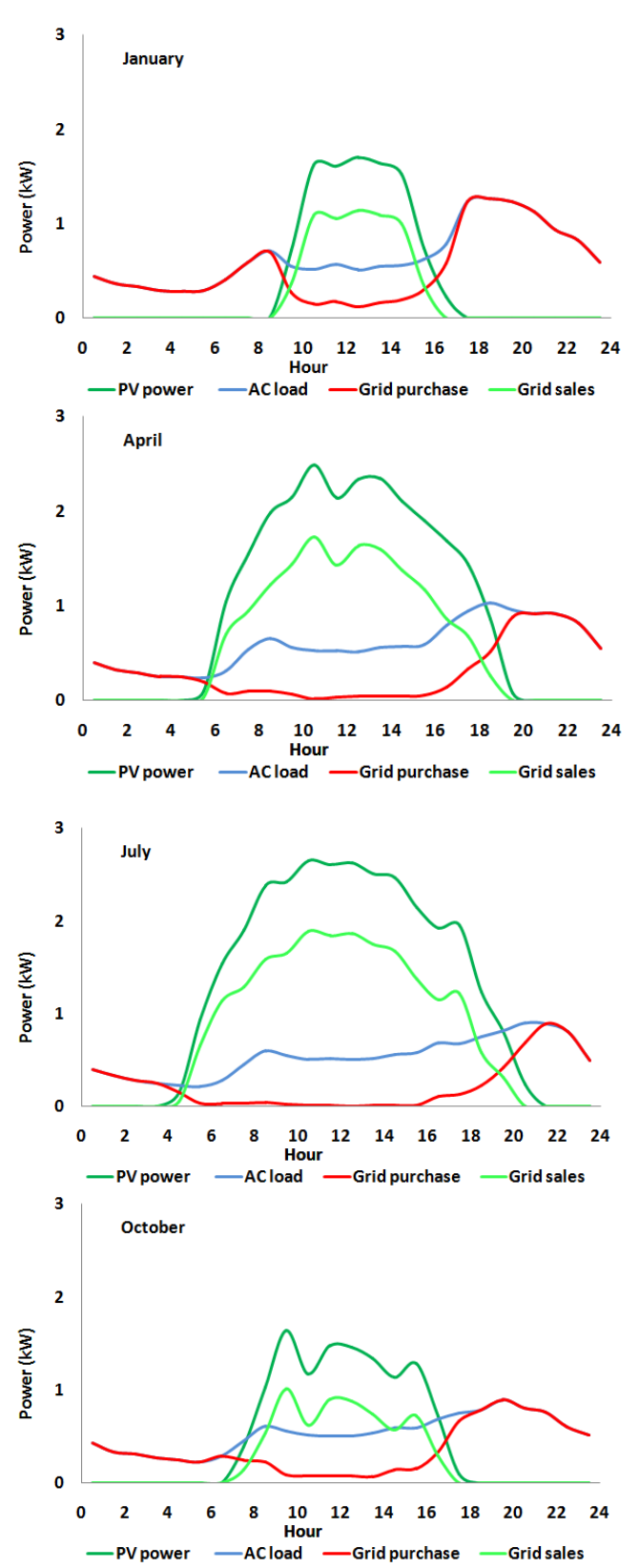

Fig 9: Hourly averaged load profile (AC load), energy production (PV power), sell to (Grid sales) and purchase from grid (Grid purchase) - Two axis tracking system.

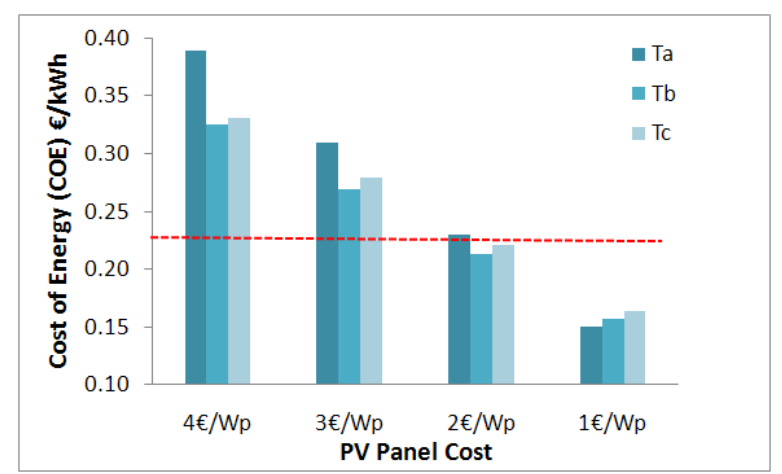

Fig 10: Comparative study of $\mathrm{COE}$ for $\mathrm{Ta}$ - fixed axis, $\mathrm{Tb}-1$ axis tracking, $\mathrm{Tc}-2$ axis tracking system and grid electricity cost - red dotted line 
Another finding is that, because of the hourly difference between the load demand and solar radiation availability, user has to purchase the grid electricity every single day. Hourly averaged load profile along with the energy production from the $\mu$ Gen system, energy sell to the grid and energy purchase from the grid is shown in Fig 8 and 9. Both have been given for four months (Jan, Apr, Jul and Oct). Fig 8 represents the performance for fixed axis tilt with 53 degree. Fig 9 reflects the similar performance for two axis tracking system. It shows that for all cases and for any day of the year, the user has to purchase electricity from the grid. There could be a possibility to store the additional sold energy in storage system and use it during the peak demand or solar radiation shortage time. But this storage system can then increase the cost of the system and thus can also increase the COE.

TABLE V

ENERGY PURCHASED AND SOLD FOR $6 \mathrm{KW}$ PV BASED $\mu$ GEN SYSTEM (1-AXIS AT $53^{\circ}$ ANGLE AND 2 AXIS TRACKING SYSTEMS)

\begin{tabular}{|l|l|l|l|l|l|l|}
\hline \multirow{2}{*}{ Month } & \multicolumn{2}{|l|}{$\begin{array}{l}\text { Energy Purchased } \\
\text { (kWh) }\end{array}$} & \multicolumn{2}{l|}{$\begin{array}{l}\text { Energy Sold } \\
\text { (kWh) }\end{array}$} & \multicolumn{2}{l|}{$\begin{array}{l}\text { Net Purchases } \\
(\mathrm{kWh})\end{array}$} \\
\cline { 2 - 7 } & $\begin{array}{l}\text {-axis } \\
\text { track }\end{array}$ & $\begin{array}{l}2 \text { axis } \\
\text { track }\end{array}$ & $\begin{array}{l}1 \text {-axis } \\
\text { track }\end{array}$ & $\begin{array}{l}\text { 2 axis } \\
\text { track }\end{array}$ & $\begin{array}{l}1 \text {-axis } \\
\text { track }\end{array}$ & $\begin{array}{l}2 \text { axis } \\
\text { track }\end{array}$ \\
\hline Jan & 399 & 402 & 189 & 201 & 210 & 201 \\
\hline Feb & 294 & 297 & 248 & 259 & 47 & 38 \\
\hline Mar & 259 & 261 & 401 & 617 & -342 & -356 \\
\hline Apr & 220 & 222 & 452 & 460 & -232 & -238 \\
\hline May & 187 & 189 & 692 & 712 & -505 & -523 \\
\hline Jun & 155 & 156 & 635 & 657 & -480 & -501 \\
\hline Jul & 167 & 169 & 620 & 641 & -453 & -471 \\
\hline Aug & 200 & 202 & 487 & 498 & -286 & -296 \\
\hline Sep & 236 & 239 & 335 & 339 & -99 & -101 \\
\hline Oct & 268 & 272 & 199 & 204 & 68 & 67 \\
\hline Nov & 307 & 311 & 183 & 193 & 124 & 118 \\
\hline Dec & 364 & 367 & 122 & 130 & 242 & 237 \\
\hline Annual & 3,057 & 3086 & 4,762 & 4,910 & $-1,704$ & $-1,824$ \\
\hline
\end{tabular}

Fig 10 shows the COE for a $6 \mathrm{~kW}$ PV based $\mu$ Gen system for different PV panel cost $(1-4 € / \mathrm{Wp})$. It is observed that for fixed axis system COE is higher than the other two systems when PV panel cost is $(2-4 € / \mathrm{Wp})$. On the other hand COE in 1 -axis tracking system is lower than that of 2-axis tracking system. The reasons might be that, (i) in 2-axis tracking system, obtained solar radiation does not improve significantly in Irish climatic condition and (ii) the cost difference between 1-axis and 2-axis tracking system is high compared to the system performance. Therefore, 2-axis system may not be cost effective in Irish environment.

When the panel cost decreases to $2 € / \mathrm{Wp}$ then COE in fixed axis system becomes closer to the grid electricity cost. Tracking system becomes sustainable at that condition. When panel cost is lower than $2 € / \mathrm{Wp}$ then it is expected that fixed and tracking both systems can become viable.
When panel cost becomes $1 € / \mathrm{Wp}$, fixed axis system can be better than the tracking systems. It happens because of the additional system price in the tracking system which is comparatively higher than the panel cost. It indicates that the tracking system cost should also be decreased in time.

\section{CONCLUSION}

This paper deals with the techno-economical analysis of a grid connected PV based $\mu$ Gen system in Irish environment. The goal of this task is to achieve the sustainability of this system through some technical improvement of the existing system. It is found that for fixed axis system the $\mu$ Gen can be placed at 38 degree tilt also. As the summer months have more solar radiation, therefore grid connected $\mu \mathrm{Gen}$ with 38 degree tilt could be a better choice. Because of the difference in the additional cost, $\mathrm{COE}$ for 1-axis tracking is lower than that of 2 axis tracking system. Based on the present market price and grid electricity cost, both the fixed and tracking systems can become sustainable when the PV panel cost becomes lower then $2 € / \mathrm{Wp}$. If the tracking system cost is not decreased in time, fixed axis system can show better performance when PV panel cost is reduced to $1 € / \mathrm{Wp}$.

\section{REFERENCES}

[1] Strategy for Renewable Energy:2012-20, Department of Communication, Energy and Natural Resources. http://www.dcenr.gov.ie/NR/rdonlyres/9472D68A-40F4-41B8-B8FDF5F788D4207A/0/RenewableEnergyStrategy2012 2020.pdf

[2] Howley M, Dennehy E, Gallachoir DBO, Holland M, Energy in Ireland: Sustainable Energy Authority: 2012.

[3] Zhe Li, Boyel F, Reynolds A, Domestic application of solar PV system in Ireland: The reality of their economic viability. Energy 36 (2011) 5865-5876

[4] Ayompe L.M, Duffy A, McCormac S.J, Conlon M, Projected cost of a grid connected domestic PV system under different scenarios in Ireland, using measuring data from a trail installation.

[5] Hamad AA, Alsaad MA, A software application for energy flow simulation for grid connected photovoltaic system. Energy conversion and management 51 (8), pp 1684-9, 2010

[6] S K Khadem, Feasibility study of Wind Home System in Coastal Region of Bangladesh, https://homerenergy.com/webcastdownloads/WE58 FeasibilityWHS Bangladesh.pdf

[7] A Status report on micro-generation in Ireland. http://www.seai.ie/Renewables/Microgeneration/Status_report_on_Mic rogeneration in Ireland.pdf

[8] Electric Ireland https://www.electricireland.ie/ei/residential/priceplans/1st-october-price-change.jsp

[9] Gilbert M. M, Renewable and Efficient Electric Power Systems, A John Wiley \& Sons, Inc., Publication, 2004

[10] Gay CF, Werkes JW, Wilson JH, Performance advantages of two axis tracking for large flat plate photovoltaic systems, Proc. of the $16^{\text {th }}$ photovoltaic specialists conf., San Diego, pp 1368-71, 1982.

[11] Abdallah S, The effect of using sun tracking systems on the voltage current characteristics and power generation of flat plate PV, Energy Conversion and Management, Vol. 45, pp. 1671-9, 2004.

[12] Monthly solar radiation. Met Eireann; 2012

[13] Standard load profiles, 2011, Retail Market Design Service; 2009.

[14] PV panel cost collected on 14.04.2013, http://www.windandsun.co.uk/products/219/.aspx

[15] Solar tracking system cost collected on 10.03.2013, http://www.windandsun.co.uk/products/269/.aspx\#1421

[16] Inverter cost collected on $\mathrm{http}: / /$ www.pvpower.com/inverters-over-10kw.aspx?page $=2$ 